\title{
CASE STUDY: LESSONS LEARNED IN LAUNCHING AN INTEGRATED ONLINE GRADUATE BUSINESS ANALYTICS PROGRAM
}

\author{
Mary Dunaway, Quinnipiac University, mary.dunaway@quinnipiac.edu \\ Richard McCarthy, Quinnipiac University, richard.mccarthy@quinnipiac.edu
}

\begin{abstract}
In the fall of 2014, the Quinnipiac University School of Business launched a Master of Science in Business Analytics program. The program is entirely managed including curriculum development and delivery by the Computer Information Systems department. However, an interdisciplinary committee developed the initial program proposal. This paper is a case study report that serves to establish an initial knowledge base of lessons learned in the development and implementation of graduate Business Analytics programs.
\end{abstract}

Keywords: Business Analytics, Information Systems, Graduate Programs, Online Learning

\section{INTRODUCTION}

The era of Big Data is here and business schools must expose graduates to the skills that today's analytics-based companies are seeking. A 2011 study by the McKinsey Global Institute predicts that by 2018 the United States will face a shortage of more than 1.5 million managers, analysts, and other workers who are well-versed in the principles and use of analytics [15]. In response to this expected shortfall, Master's degree programs in Business Analytics (BA) have emerged in anticipation of the talent shortage and in response to lobbying big companies [18].

Companies seek skilled workers that can help manage and analyze their data to inform decisions and maintain a competitive advantage. Companies such Amazon.com, Google, eBay, Netflix, and Wal-Mart to name a few, analyze massive amounts of data about their customers to discover new insights. Such companies are gaining competitive advantage from analytics - whether it's learning more about customer buying habits, decisions for new product offerings, or more value for its customers [9].

Davenport and Harris [9] define analytics as "the extensive use of data, statistical and quantitative analysis, explanatory, and predictive models, and fact-based management to drive decisions and actions." Analytics can be categorized into three areas based on the methods and purpose: descriptive, predictive, or prescriptive. This categorization is derived from Operations Research (OR), Management Information Systems (MIS), and statistics [12]

Descriptive analytics explores what has occurred. It involves gathering, organizing, tabulating, and depicting data and then describing the characteristics about what is being studied. This type of analytics is an extension of Business Intelligence (BI) $[3,11]$. BI is an Information Technology (IT) function that provides decision makers with dashboards, scorecards, and data cubes that provide the ability to slice and dice historical data.

Predictive analytics focuses on what will occur in the future. It includes methods such as regression analysis, customer segmentation, and decision trees. These type analytics go beyond the descriptive characteristics of the data and relationships among the variables. The techniques help to identify the associations among the variables and then predict the likelihood of an outcome of the phenomenon. Although, the associations of the variables are used for predictive purpose, explicit cause-and-effect relationships is not always necessary to make accurate decisions [10]. Furthermore, value can be gained with Predictive analytics to discover interesting and meaningful patterns in the data, identify the important factors, and explore using complex mathematical formulas outcomes to inform decision-making.

Prescriptive analytics investigates what should occur. These type analytic techniques extends beyond predictive analytics by specifying both the actions necessary to achieve predicted outcomes, and the interrelated effects of each 
decision. Such methods as experimental design and optimization, delve further to suggest a course of action or why something happened. Most organizations progress from descriptive to predictive to prescriptive analytics to shape their analytics based data.

The purpose of this case study is to provide guidance to faculty on ways to effectively integrate BA courses into a Master-level online program in a synergistic way to accomplish goals for: (1) increased student learning, (2) effective course delivery, and (3) and strategic course development. We discuss BA skills and knowledge attainment, online learning as it relates to learning BA, the development of our BA program, and conclude with offering lessons learned.

\section{Graduate Business Analytics Programs}

Programs in BA are fairly new. AACSB recommends as an Information Technology standard that students learning experiences should include the development of skills and knowledge related to data creation, data sharing, data analytics, data mining, data reporting, and storage within and across organizations [2]. Also, it is expected that graduates demonstrate the ability to effectively utilize tools and information technologies that support data analytics. One of the primary goals of a BA programs in higher education is to equip students with the knowledge and skills to learning experiences that can be leveraged by one of three types of workers: business users, business analysts, or data scientists.

INFORMS has developed a mapping of the learning to appropriate BA skills by job tasks for those who want to attain a certified analytics professional. Surveyed were employers who indicated interest in hiring analytics talent highlights. Seven key BA skill domains were developed along with an assigned percentage weight [6]. The data identifies the skills and tasks that analytic professionals typically undertake. The BA skill domains are used in their business analytic certification exam. Table 1 describes each job tasks area, percentage weight, and a brief description.

Table 1. Key BA Skill Domains

\begin{tabular}{|l|c|l|}
\hline \multicolumn{1}{|c|}{ Job Tasks Area } & Percentage Weight & \multicolumn{1}{c|}{ Description } \\
\hline Business problem (framing) & $12-18 \%$ & $\begin{array}{l}\text { The ability to understand a business } \\
\text { problem and determine whether the } \\
\text { problem is amenable to an analytics } \\
\text { solution }\end{array}$ \\
\hline Analytics problem framing & $14-20 \%$ & $\begin{array}{l}\text { The ability to reformulate a } \\
\text { business problem into an analytics } \\
\text { problem with a potential analytics } \\
\text { solution }\end{array}$ \\
\hline Data & $\begin{array}{l}\text { The ability to work effectively with } \\
\text { data to help identify potential } \\
\text { relationships that will lead to } \\
\text { refinement of the business and } \\
\text { analytics problems }\end{array}$ \\
\hline $\begin{array}{l}\text { Methodology (approach) } \\
\text { selection }\end{array}$ & $\begin{array}{l}\text { The ability to identify and select } \\
\text { potential approaches for solving a } \\
\text { business problem }\end{array}$ \\
\hline Model building & $12-18 \%$ & $\begin{array}{l}\text { The ability to identify and select } \\
\text { potential approaches for solving a } \\
\text { business problem }\end{array}$ \\
\hline Deployment & $\begin{array}{l}\text { The ability to deploy the selected } \\
\text { model to help solve a business } \\
\text { problem }\end{array}$ \\
\hline Model life cycle management & $\begin{array}{l}\text { The ability to manage the model } \\
\text { life cycle to evaluate the model's } \\
\text { business benefit over time }\end{array}$ \\
\hline
\end{tabular}




\section{Online Learning of Business Analytics}

Online teaching has become increasingly popular at many higher education institutions. As of 2015, approximately 77 institutions have launched Master Degree programs in BA and Data Science. Approximately, 27 of these institutions offer programs online [16]. Over 6.7 million students take at least one online course and $32 \%$ of current higher education students have taken one course online. Moreover, $69 \%$ of higher education institutions affirm online learning is a critical part of their long-term strategy [5].

Many IS/IT instructors who are teaching BA are new to teaching in the online environment. It is recognized that effective faculty are key to student success in online courses. New faculty in this domain of learning needs orientation and training in designing, developing, teaching, and assessing courses in this discipline. It is often a challenge to deliver the course content in the online environment [13]. Substantial concerns have been raised with the quality of online education compared with face-to-face classes $[4,17,19]$. Though studies have shown neither delivery method was more effective than the other with regard to students' achievement or their perception of course effectiveness [14], [7]. Thus, it is important to provide a case study giving a deeper analysis of launching a BA program that may reveal useful information to benefit prospective universities.

\section{Development of the Business Analytics Program}

Since 2012 there have been many graduate business analytics programs launched by colleges and universities throughout the United States. Some have differing focuses depending upon the host department/school. During the 2012-2013 academic year, the Quinnipiac University School of Business decided to develop and launch an interdisciplinary Master of Science in Business Analytics Program. A committee was formed with representatives from their economics, accounting, finance, management, entrepreneurship and marketing departments. The associate dean for graduate studies chaired the committee. The representatives of the departments had extensive experience teaching online in a Master of Science in Business Administration program. A curriculum proposal was developed that primarily focused on taking advantage of existing required and elective MBA courses. The curriculum proposal was general in scope with very broad outcomes and no discussion of the tools and techniques that would be used to achieve the outcomes. After the proposal was approved, there was discussion to decide who would be responsible for administering the program. The primary architects of the proposal declined to take on the role of administering the program. After consultation with the faculty of the Computer Information Systems department, it was decided that they would assume responsibility.

\section{Lessons Learned}

In his highly successful book, The Seven Habits of Highly Effective People, [8] the second habit that he points out is "begin with the end in mind". When developing a program that serves an interdisciplinary student population, begin first by defining what the learning outcomes of the program are and who the target audience is. Our target audience of current BA professionals are looking to expand their skillset through a very in depth understanding of the techniques used to analyze data which seeks a different curriculum than students who are just getting started as business analysts. This situation, when trying to combine both groups' results in providing poor service to both. For the first group, the pace is to slow and for the latter group it is too fast. It was always the intention of the program to focus on target audience who was new or entering the analytics field. This focus was emphasized with the marketing of the program.

One of the first items addressed by the program faculty was to clearly define learning outcomes for the program that were specific and measurable. This guided a review of the initial curriculum proposal to evaluate the content and descriptions of the courses and to identify gaps in addressing the outcomes. The initial course was changed from a general course in statistics and probability theory to one that focused on introducing business analytics by using statistical techniques to solve business problems. This provided the advantages of setting the foundation of technical tools that the subsequent courses would as well as it created a foundation of understanding core concepts that would be used in subsequent courses. An additional benefit was noted by the team responsible for marketing the program - it's a challenge to get most people excited about a program when the very first course is titled: Probability and Statistics. 
The primary program learning outcomes consisted of:

1. Understand different techniques used to analyze data

2. Understand how data is stored, accessed, and retrieved

3. Apply business analytics techniques and utilize analytical tools for organizational decision-making

4. Demonstrate skills in interpreting and presenting analytical results

These were developed after the curriculum proposal was approved. This created a disconnect, particularly for the learning outcome related to demonstrating skills in interpreting and presenting analytical results. One of the primary courses that addressed this outcome was initially implemented as an elective; this has since been changed.

The initial program proposal did not provide any direction or prescription of tools that would be used in the program. The faculty review team decided to use SAS, Microsoft SQL Server, Microsoft Excel, and Tableau as the computing platform partially because of their adoption by organizations where the students work and partially because their academic alliances make the products accessible at little to no cost. An additional benefit to the students is that SAS has an alliance program with colleges and universities that permits the granting of a joint SAS certification.

\section{CONCLUSIONS AND CALL FOR RESEARCH}

Launching a BA program is heavily time and resource consuming, and can be a source of frustration on the part of faculty and students. Compiling Lessons Learned can provide guidance to those institutions that may be considering starting a BA program or struggling to get their program off the ground. Lessons Learned provide benefit to help avoid problems in future situations and provides a knowledge sharing environment. Also, improvements can be gained for content and pedagogy. Most importantly, establishing a BA program where the learning environment is conducive for students to thrive and develop the necessary BA skills that has immediate impact in their future job.

We have compiled an initial list of Lessons Learned based on our experiences to launch an online BA program at our university. Listed below are key the lessons learned:

\section{Faculty-Centered}

- Utilize Best practices for on-line pedagogy

- Establish a unique aspect about your program

- Don't re-invent the wheel, do what works

- Utilize the "Rule of Three" for course development

- Develop and maintain helpful relationships

- Ask for Help

- Begin with the end in mind

- Obtain the appropriate BA technology academic training

\section{Student-Centered}

- Let students learn from their mistakes

- Utilize applicable real-world problem-solving

- Seek feedback early and often

- Re-calibrate expectations and revise as needed

According to Gorman \& Klimberg many of the current BA programs are quite heterogeneous [12]. Most programs tend to have their own individual definition of BA based on the subject matter offering. Additionally, many BA programs have simply rebranded or repurposed existing curriculums and programs. Given the disparate nature of this new phenomenon, our research serves as a call to action to encourage faculty in BA programs to develop and share their best practices. In doing so, allows programs to adapt their specific circumstances or environments in an area where research or evidence may be absent or incomplete.

In this new domain of learning, there is a need to develop a repository of cases and other educational material in this subject area. We expect that there will even be peer reviewed case study journals, empirical and theoretical studies 
that will emerge. This type call for research not only helps universities and their faculty, but also the industries at large where students who earn BA skills will have immediate impact for their current or future employment.

\section{REFERENCES}

1. AACSB. (2015a). Quality issues in distance learning. Retrieved from http://www.aacsb.edu/ /media/AACSB/Docs/Accreditation/Standards/2013-business-standards.ashx

2. AACSB. (2015b). Accreditation standards: A7. Retrieved from http://www.aacsb.edu/en/accreditation/standards/2013-accounting/learning-and-teaching-standards/standard7/

3. Abbott, D. (2014). Applied predictive analytics: Principles and techniques for the professional data analyst. Somerset, NJ, USA: Wiley.

4. Abdous, M. (2010). Operationalizing quality assurance in E-learning: A process-oriented lifecycle model. Proceedings of Global Learn, 731-736.

5. Allen, I. E., \& Seaman, J. (2013). Changing course: Ten years of tracking online education in the United States. ERIC.

6. Candidate handbook - INFORMS Retrieved from https://www.informs.org/Certification-ContinuingEd/Analytics-Certification/Candidate-Handbook.

7. Carrol, N., \& Burke, M. (2011). Learning effectiveness using different teaching modalities. American Journal of Business Education (AJBE), 3(12).

8. Covey, S. R. (1989). The 7 Habits of Highly Effective People.

9. Davenport, T. H., \& Harris, J. G. (2007). Competing on analytics: The new science of winning Harvard Business Press.

10. Davenport, T. H., \& Kim, J. (2013). Keeping up with the quants: Your guide to understanding and using analytics, Harvard Business Review Press.

11. Franks, B. (2014). The analytics revolution. Hoboken, New Jersey: John Wiley \& Sons, Inc.

12. Gorman, M. F., \& Klimberg, R. K. (2014). Benchmarking academic programs in business analytics. Interfaces, 44(3), 329-341.

13. He, W., Xu, G., \& Kruck, S. (2014). Online IS education for the 21 st century. Journal of Information Systems Education, 25(2), 101.

14. Jahng, N., Krug, D., \& Zhang, Z. (2007). Student achievement in online distance education compared to faceto-face education. European Journal of Open, Distance and E-Learning, 1, 19.

15. Manyika, J., Chui, M., Brown, B., Bughin, J., Dobbs, R., Roxburgh, C., \& Byers, A. H. (2011). Big data: The next frontier for innovation competition and productivity. New York: McKinsey Global Institute.

16. Master of Science in analytics $\bullet$ institute for advanced analytics $\bullet$ North Carolina state university $\bullet$ directors blog - degree programs in analytics and data science Retrieved from http://analytics.ncsu.edu/?page_id=4184.

17. Rovai, A. P., \& Downey, J. R. (2010). Why some distance education programs fail while others succeed in a global environment. The Internet and Higher Education, 13(3), 141-147.

18. Thibodeau, P. (October 8, 2012), Grad schools add big-data degree. Computerworld, 6.

19. Yang, Y. (2010). Roles of administrators in ensuring the quality of online programs. Knowledge Management \& E-Learning: An International Journal (KM\&EL), 2(4), 363-369. 